\title{
Arsenic-free water still a pipedream
}

Decontamination plants installed at wells throughout West Bengal are failing to reduce arsenic in local drinking water to safe levels, according to a report. The authors suggest that efforts to supply safe water should instead focus on purifying surface water.

Of 18 arsenic-removal plants monitored over a two-year period, none reduced arsenic levels below the maximum safe value stipulated by the World Health Organization (WHO), says epidemiologist Dipankar Chakraborti of Jadavpur University in Calcutta, India, whose team carried out the tests (M. A. Hossain et al. Environ. Sci. Technol. 39, $4300-4306 ; 2005)$. The findings come as a blow to efforts to address what has been called the worst mass poisoning in history, in which millions of people were exposed to dangerous or fatal levels of arsenic in their water.

The high levels of arsenic in well water used for drinking and irrigation came to light in the early 1990s, after outbreaks of skin disease and cancers in West Bengal and Bangladesh. The arsenic comes from natural geological sources that weren't recognized when the wells were dug during the 1970s. An estimated 35 million people were drinking from such wells, dug by aid agencies so that locals wouldn't have to rely on rain and river water, which is often contaminated by carriers of diseases such as typhoid and dysentery.

To try to fix the situation, some 2,000

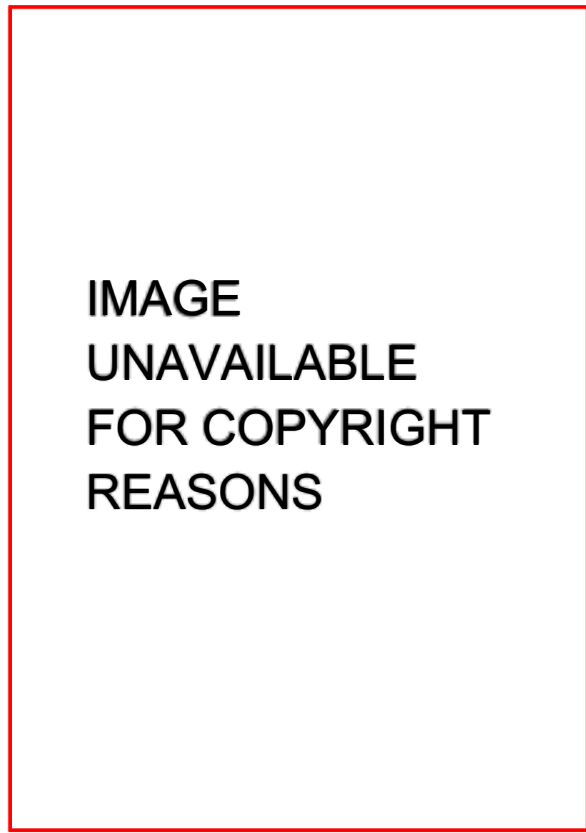

Hard to swallow: millions of people in West Bengal are still drinking highly contaminated water.

arsenic-removal plants were installed in wells in West Bengal, and many more in Bangladesh, at an average cost of US $\$ 1,500$ each. These plants aim to remove arsenic from water using a series of filters and extraction systems.

But controversy has persisted. Chakraborti has previously shown that methods for identi- o fying safe wells are not always reliable. Now he says that the removal plants cannot be trusted either.

Chakraborti and his colleagues tested 18 such plants, from 11 different manufacturers in India, Germany and the United States. The average arsenic concentration in water treated during a two-year period was 26 micrograms per litre - more than twice the value recommended by the WHO. Only two of the plants met the Indian standard value for arsenic levels, which is five times higher than that of the WHO, and $80 \%$ of the local villagers tested had abnormal levels of arsenic in their urine.

Chakraborti believes that efforts should now focus on harnessing and purifying surface water. The United Nations Children's Fund (UNICEF), which initiated and funded the original well-drilling programme, supports the approach. "We're really pushing for rainwater harvesting," says UNICEF emergencies coordinator Paula Plaza.

However, there are now plans to test arsenicremoval plants more thoroughly before they are licensed for use. A Canadian company called the Ontario Center for Environmental Technology Advancement is collaborating with the Bangladeshi government to develop performance standards for these systems. Philip Ball

\section{Malaysia plans 'red book' in its attempts to go green}

KUALA LUMPUR

Malaysia, criticized in the past for being a poor steward of its biodiversity, seems to be turning over a new leaf.

Biodiversity experts from across the country met in Kuala Lumpur last month to hammer out a plan that would catalogue the country's thousands of plant and animal species.

Malaysia is one of the most biologically diverse countries in the world. It is thought to host around 15,000 different plant species, although only about half that number have been found and listed. But the country has become infamous in recent decades for dearing rainforests and draining peat swamps to grow palm trees - it now produces around half of the world's supply of palm oil. The effect of this on the country's biodiversity is not known.
The international Convention on Biological Diversity has been pressuring Malaysia to come up with conservation strategies since it came into force in 1993, withlittle result. But Dato' Seri Abdullah

IMAGE
UNAVAILABLE
FOR COPYRIGHT
REASONS

Malaysia's drive to grow palm trees for palmoil has haduntoldeffects on the country's biodiversity.
Ahmad Badawi, who became prime minister in 2003, is said to be more sympathetic than his predecessor to ecological issues. In particular, he is keen to use the country's biodiversity to drive drug development.

That momentum, and associated funding, has led to a project to create a national 'red book. This would catalogue which species are present and where, as well as listing any threats they face. The project will be overseen by Saw Leng Guan of the Forest Research Institute of Malaysia near Kuala Lumpur.

But Peter $\mathrm{Ng}$, a conservation biologist at the National University of Singapore, says Malaysia will be a tough nut to crack because knowledge is so fragmented. Drastic funding cuts in the 1990 s also left the country with few taxonomists. "We have money, but we need people to do the work," he says. David Cyranoski 